\title{
Development of biosensor based on imaging ellipsometry
}

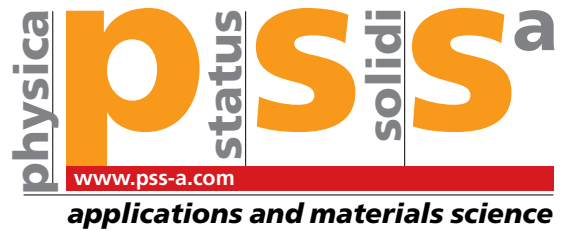

\section{G. Jin*}

Institute of Mechanics, Chinese Academy of Sciences, \#15, Bei-si-huan west Rd., Beijing 100080, P.R. China

Received 9 June 2007, revised 25 January 2008, accepted 28 January 2008

Published online 20 March 2008

PACS 07.07.Df, 07.60.Fs

"e-mail gajin@imech.ac.cn, Phone: +86 108254 4138, Fax: +86 1082544138

The concept of biosensor based on imaging ellipsometry was proposed ten years ago. Its principle and the methodology as well as some solutions to problems which have to be faced during the development are mentioned. Its properties of phase sensitive, high throughput and fast sampling, as well as labelfree, sensitivity better than $1 \mathrm{ng} / \mathrm{ml}$ for Immunoglobulin $\mathrm{G}$, and real-time analysis for protein interaction process, etc. provide a potential for applications in biomedicine field. The recent biosensing development with total internal reflection imaging ellipsometry is presented also.

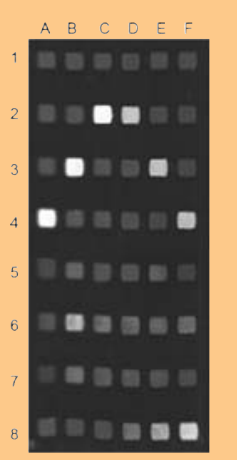

An example of 48 protein arrays in matrix.
1 Introduction The biosensor concept based on imaging ellipsometry for visualization of biomolecular interactions was reported in 1995 [1, 2]. In order to develop it into a practical technique $[3,4]$ for protein analysis or protein detection, a lot of problems had to be faced, such as the ligand immobilization - probe biomolecule assembled on substrate surface, the protein delivery - reagent and sample solution transferring, the biomolecule affinity presentation on chip - binding force effect between biomolecules shown on the chip, the specific interaction specific binding between ligand and receptor, the unspecific binding influence - other binding effect except the specific binding, the detection sensitivity - the minimum detectable concentration of target biomolecule, the sample consumption amount, the sampling and calibration for quantitative detection, etc. It is composed of a microfluidic array reactor and a reader with imaging ellipsometry automatically controlled by a PC computer. It has become a practical technique for protein detection with functions of label-free, high throughput, real-time detection for protein interaction process and quantification, etc. [5].

\section{InterScience}

\section{Experimental details}

2.1 Principle Imaging ellipsometry was used to visualize the molecule mass surface concentration distribution of protein layers attached on a patterned surface on a solid substrate as shown in Fig. 1. A ligand and its receptor such as an antibody and its corresponding antigen could assemble into bio-complexes due to their affinity. The optical biosensor was based on that each reactant as a ligand was immobilized to a surface to form a monolayer as a bioprobe with its bioactivity. The other reactant as the analyte (or receptor) existed in a solution. The bioprobe was exposed to the solution containing analyte. When the analyte in the solution interacted with its corresponding ligand on the bioprobe and assembled into complex upon their affinity. The molecule mass surface concentration on the surface where the interaction takes place became higher than before exposure to the analyte solution. A significant increase of the surface concentration indicated that the solution contained the receptor against the ligand on the surface. With the visualization of imaging ellipsometry, which has a high spatial resolution in the order of 0.1 nano-meter in vertical and micron in lateral, the increase could be de- 


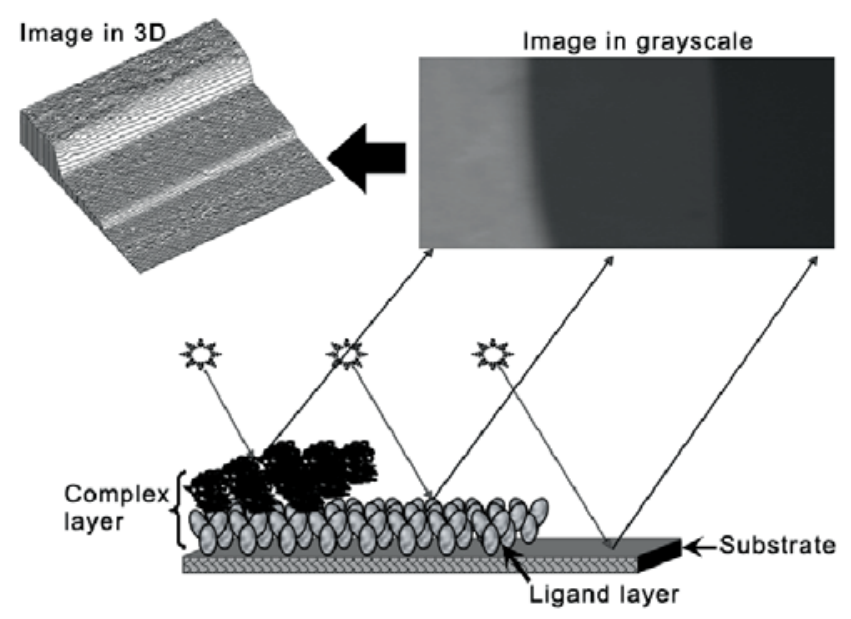

Figure 1 Model of bioprobe based on imaging ellipsometry. The incident wave of polarized light as probe beam irradiates the sample and is modified, which makes the reflective beam carry sample information, such as protein molecule mass surface concentration. The sample includes three parts: the bear substrate, the ligand layer and complex layer on the substrate, which can be seen in ellipsometric image with the value of reflection intensity in grayscale. The variation of the protein surface concentration causes the value in grayscale of the image changed. The surface concentration distribution of protein layer can be easily seen in three dimensions.

termined, and in this way, the existence of the analyte in the solution could be verified. Many bioprobes arrayed in matrix to form a protein micro-array was used for multidetection [3-5].

2.2 General structure of the biosensor based on imaging ellipsometry Figure 2 gives the schematic diagram of a general structure of the biosensor based on imaging ellipsometry.

The biosensor was combined with several parts that are the control system, the microfluidic reactor array, the imaging ellipsometer as a reader and the biosensor database as well as software automatically to run the biosensor.

The control system has functions of hardware motion control and image acquisition, played crucial role for the performance and operation of the biosensor as an automatic system. A PC computer was used as the operation platform and data processor. Under the operation of homemade software, a motion control card inserted in the computer produced motion signal for motor driver. The mechanical motion parts in microfluidic array reactor and the imaging ellipsometer powered by the motor were driven automatically when needed. An image board inserted in the computer was used to transfer the image signal captured with imaging ellipsometer to a digital format.

The microfluidic array reactor was designed for protein array fabrication and biomolecule interaction. A microfluidic array containing many channels was used for transferring fluid to the sensing surface and forming a protein array [6]. Each channel has independent inlet and outlet, which can be used individually to deliver solutions to each spot of the array and covalently immobilize ligand on surface simultaneously. The fluid such as protein solution, purified water, rinsing fluid in each test tube was transferred to the microfluidic array by a peristaltic pump successively.

A protein array prepared by the microfluidic reactor was used for multi-protein interaction detection, and then, the protein microarray would be visualized by the imaging ellipsometer for protein detection. The imaging ellipsometer was based on a configuration of Polarizer-Compensator-Specimen-Analyzer (PCSA). The probe light beam with single wavelength was extended and collimated to ensure that each point in the field of view of the protein array has the same angle of incidence. In order to carry out the quantitative measurement, off-null ellipsometry sampling method [2] was used due to its fast speed in the order of sub-second. The protein array was imaged by a lens into a 2D imaging sensor which transfers the image signal into computer and form a digital image for further analysis. Under the operation of control system, the imaging ellipsometer system featured some automatic functions including the auto-focusing, the setting of polarizer, analyzer, compensator and the variation of the angle of incidence, etc.

The biosensor database was crucial for the biosensor operation and applications. It has several functions: (i) Re-

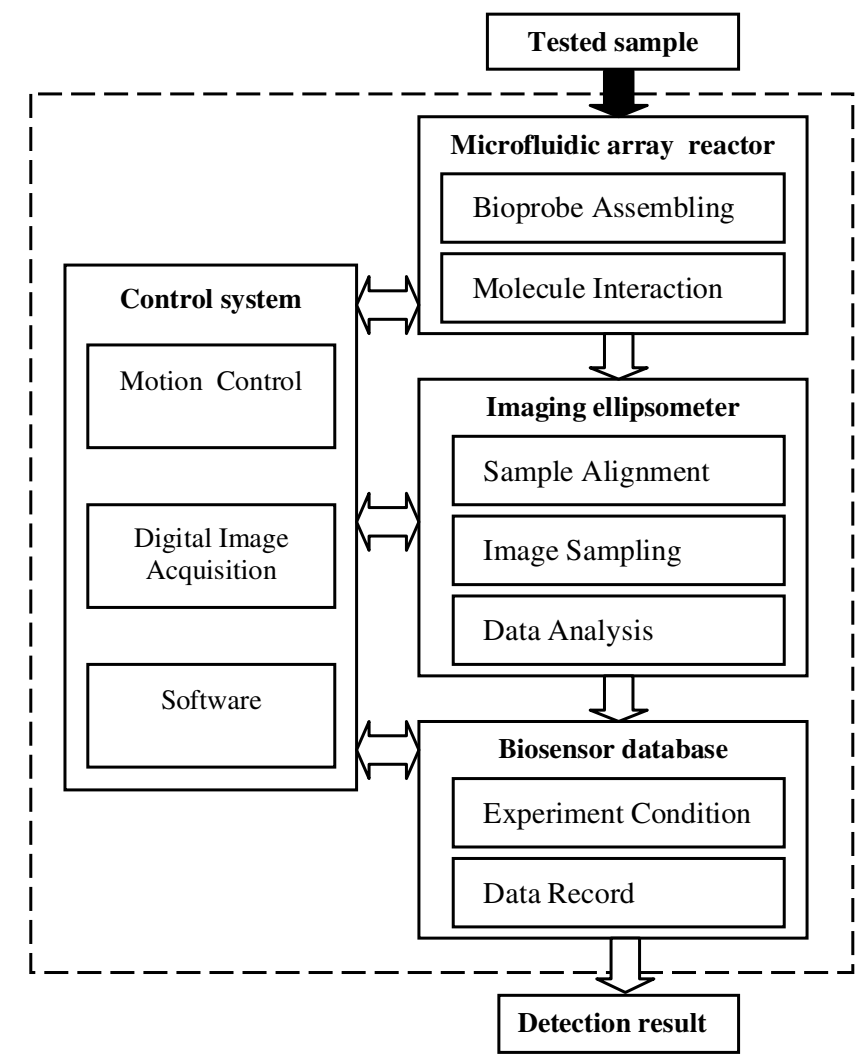

Figure 2 Schematic of biosensor based on imaging ellipsometry. The solid arrow indicates the physical flow of a sample, the hollow arrows indicate the data flow. 
cord and analysis of measurement conditions in microfluidic array reactor and imaging ellipsometer, such as the fluid speed, reaction time, and polarizing parts (polarizer, analyzer, compensator) setting, etc. (ii) Record of the data of analyte, such as the bio-specificity, the molecule mass, concentrations, and corresponding ligand, etc.

2.3 Surface modification and ligand immobilization In the biosensor, the immobilization of biomolecules at interfaces played a crucial role. It had two kinds of obvious functions: one was the presentation of ligand on the biosensing surface; another was to prevent unspecific binding. At the early stage of the biosensor, the ligand immobilization was done by physical adsorption. The use of such attachment techniques involved certain limitations. The immobilized proteins suffered partial denaturation and tended to leach or wash off the surface [7, 8]. In some cases, the adsorbed protein was replaced from the surface by other more active protein, because of the competitive adsorption of proteins $[9,10]$. To overcome these problems, the covalent immobilization was the preferred method of attaching proteins to silicon surface due to the strong, stable linkage. We investigated the feasibility of using 3-aminopropyltriethoxysilane (APTES) to modify silicon surface and then activated with glutaraldehyde to immobilize protein covalently for the biosensor based on imaging ellipsometry as an alternative to the direct physical adsorption [11]. This protein immobilization method had been used successfully in other immunoassay techniques [12-15]. In order to obtain high bioactivity of ligand on the bioprobe, the oriented immobilization of ligand had to be done. Several techniques for the surface modification and ligand immobilization had been developed.

2.3.1 Surface modification with dichlorodimethylsilane [11] Surface modified with this method is highly hydrophobic, proteins immobilized mainly through hydrophobic interaction between proteins and surfaces. The protein adsorption amount is higher than that on hydrophilic modified surfaces, but immobilized proteins would be desorbed to some extent.

2.3.2 Oriented immobilization of immunoglobulin by Protein A [16] The hydrophobic surface treated with dichlorodime-thylsilane is first incubated in protein A solution. The protein A modified surface is then blocked with bovine serum albumin, and incubated in antiimmunoglobulin G or immunoglobulin G solution. Protein A could selectively bind the Fc region of antibody. The amount of Immunoglobulin $\mathrm{G}$ bound with anti-Immunoglobulin $\mathrm{G}$ immobilized by the protein A on silicon surface is much more than that bound with anti-Immunoglobulin $\mathrm{G}$ immobilized by physical adsorption. Also Immunoglobulin $G$ immobilized on protein $A$ could bind more antibody. The existence of protein A layer is effective to isolate the Immunoglobulin $\mathrm{G}$ from the surface, so that the bio-activity of Immunoglobulin G would be kept well. The protein A layer has another function for the antibody purification from solutions since only the $\mathrm{Fc}$ region of antibody may bind to protein A, but not other proteins without the Fc region.

2.3.3 Modification with aminopropyltriethoxysilane (APTES) and glutaraldehyde [11] This method could immobilize proteins covalently. The higher density and stability of immunoglobulin $\mathrm{G}$ layer can be obtained on the APTES and glutaraldehyde modified surface than dichlorodimethylsilane modified surfaces.

2.3.4 Modification with a mixed silane layer [17] Hydrophilic silicon surfaces are reacted with a fresh ethanol solution of aminopropyltriethoxysilane (APTES) and methyltriethoxysilane (METS) $(1: 30, \mathrm{~mol} / \mathrm{mol})$. This procedure render the surface medium hydrophobic. Through the reaction of glutaraldehyde with APTES, proteins is covalently immobilized on the surfaces. Compared with the only APTES or MTES treated surfaces, the Immunoglobulin G covalently immobilized on the mixed silane surface may retain their structures well and binds more antibody molecules.

2.3.5 Modification with aminopropyltriethoxysilane (APTES) and succinic anhydride [18] Hydrophilic silicon surfaces are treated with a fresh ethanol solution of aminopropyltriethoxysilane (APTES) to form a highly hydrophobic surface with densely packed amino groups on the silicon dioxide of silicon substrate. After rinsed in ethanol, the surfaces are incubated in saturated solution of succinic anhydride and ethanole. The $\mathrm{CH}_{2} \mathrm{CH}_{2} \mathrm{COOCO}$ of succinic anhydride reacts with $-\mathrm{NH}_{2}$ of $-\mathrm{O}-\mathrm{Si}(\mathrm{OH})_{2}-\left(\mathrm{CH}_{2}\right)_{3}-\mathrm{NH}_{2}$ immobilized on the surfaces and results in $-\left(\mathrm{CH}_{2}\right)_{3} \mathrm{NH}-\mathrm{CO}\left(\mathrm{CH}_{2}\right)_{2}-\mathrm{COOH}$. After the surface modification, the silicon surface is activated by the mixed solution of the concentration of $0.05 \mathrm{~mol} / \mathrm{ml} \mathrm{N}$-hydroxysuccinimide (NHS) and $0.2 \mathrm{~mol} / \mathrm{ml} \mathrm{1-(3-Dimethyl-}$ aminopropyl)-3-ethylcarbodiimide hydrochloride (EDC). Under EDC existence, the reaction between carboxyl and NHS can be catalyzed on the surface, which may facilitate the binding of proteins with amino group.

2.3.6 Modification with polymerization of oligo (ethylene glycol) methyl methacrylate (OEGMA) and succinic anhydride $[19,20]$ The surface-initiated atom transfer radical polymerization (SIATRP) of oligo (ethylene glycol) methyl methacrylate (OEGMA) successfully produces polymer coatings on silicon oxide that has excellent protein resistance in a biological milieu. The level of serum adsorption on these coatings is below the detection limit of ellipsometry. The above surface is incubated in saturated solution of succinic anhydride and ethanol in order to make carboxyl groups activated by NHS + EDC to bond protein covalently. Its property is to resist protein non-specific binding. 
2.4 Micro-fluidic and biomolecule reactor-array The importance of protein micro-array in biological research is presented in many literatures [21-23], but most of them are analogous with DNA chips in terms of fabrication and detection. To get quantitative and reliable result, the spots on protein chip should have a homogeneous surface layer and the same size. It is hardly to get perfect spots by spotting or printing technique currently used in protein array fabrication [24]. A significant time-dependent slowdown of binding is often observed in protein array detection, which can be due to mass transport limitations in static conditions [25].

A surface pattern and sensing surface fabrication is an important approach for the biosensor, which should satisfy with the request of convenient, fast, low consumption and low cost. Figure 3 show a model of protein microarray biosensor based on imaging ellipsometry. A microfluidic array for multi-protein detection is fabricated [6]. The centre part is a micro-cell array sealed with a substrate surface to form a micro-reactor array. Each micro-cell has a volume of about $100 \mathrm{nl}$ and solutions can be pumped into and out of it for ligand immobilization and biomolecule interaction. Proteins may be patterned homogeneously on substrate in array format by the microfluidic system, which is favor of getting reliable data by the array biosensor based on imag-

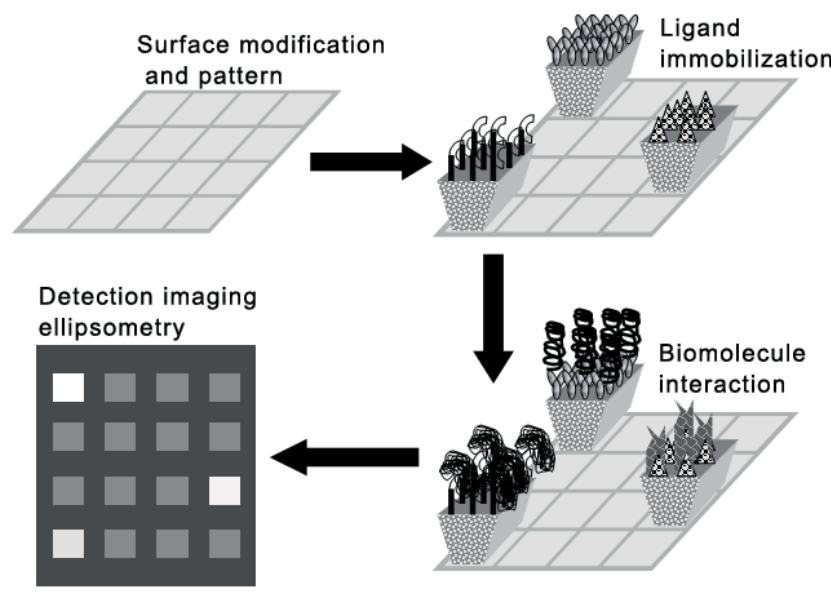

Figure 3 Model of protein microarray biosensor based on imaging ellipsometry. On the modified surface of a silicon substrate, antibodies (or antigen) as ligands can be covalently immobilized to each patterned areas. In this case, each area of the microarray may function as a bioprobe. Each one can capture its corresponding antigens (or antibodies) in the solution. When the corresponding antigens (or antibodies) in the solution interact with the bioprobe in the microarray, they would form a complex upon their affinity and the surface concentration of the layer covering the surface area of the interaction becomes higher. A significant increase in the attached layer indicates that the solution contains the antigen (or antibody). The imaging ellipsometry is used to detect the protein layer pattern on the microarray surface. The distribution of the lateral protein layer pattern is simultaneously detected, which may further point to the existence of antigens (or antibodies) in the tested solution. ing ellipsometry. The flow of protein solutions in microfluidic system may minimize the mass transport limitation effectively and the time for protein array fabrication or reaction (within $30 \mathrm{~min}$ ) is reduced greatly. After preparation, the protein array can be packed in the microfluidic system which is full of buffer so that proteins are not exposed to denaturing conditions. With simple microfluidic channel junction, the protein microfluidic array is used in serial or parallel format to analyze single or multiple samples simultaneously. An interesting advantage of the microfluidic system is that it can be used repeatedly for protein array fabrication and reaction, which largely reduces the cost of protein array, test time and consumption of proteins $(\leq 10 \mu \mathrm{l})$ as well as brought the detection sensitivity for immunoglobulin to a level better than $1 \mathrm{ng} / \mathrm{ml}$.

An $8 \times 6$ biomolecule reactor-array has been recently developed as a promising technique for parallel protein test.

\subsection{Automatic system of imaging ellipsometry}

The array biosensor based on imaging ellipsometry is a fast and convenient detection technique for protein analysis. Multiple analytes can be detected simultaneously and samples can be measured directly without requiring any labelling. Imaging ellipsometry is an enhancement of standard single-beam ellipsometry, which combines the power of ellipsometry with microscopy and works in the off-null mode. The imaging ellipsometry used in this study is an automated one, and ellipsometric conditions can be controlled by auto-adjusting the polarizer and the analyzer; the angle of incidence is variable from $45^{\circ}$ to $90^{\circ}$ with a resolution of $0.05^{\circ}$; a magnification of image to object is modulated according to the dimension of the field of view, so that the lateral resolution of micron can be reached; the auto-focusing is realized with the standard of the Laplacian algorithm [26]. All the adjustments are carried out automatically with micro-stepping motors controlled by a computer with homemade software. With the same software, the digital images in gray scale format ( 8 bits, $0-255$ grayscale or 10 bits, 1024 grayscale) are also automatically captured and processed. The light source is a xenon lamp, and a specific collimating system is used to provide an expanded parallel probe beam with a diameter of about $25 \mathrm{~mm}$. The beam passes through a polarizer and a compensator (a quarter wave plate) and finally onto the sample. An optical monochromator with a wavelength range of $400-700 \mathrm{~nm}$ and the bandwidth of $5-10 \mathrm{~nm}$ variable is placed in the incident optical passage to select a wavelength in order to obtain a high ellipsometric contrast in images. The reflection beam passes through an analyzer and an imaging lens with a spatial filter located at its focus plane, and then the ellipsometric image is focused onto the sensing area of the CCD camera. For a sample with lateral distribution of layer thickness (or surface concentration), null ellipsometry can not be carried out over the entire surface simultaneously due to the fact that different areas yield different polarization changes. To overcome the problem, the optical components in the biosensor are ad- 
justed to an off-null ellipsometric condition, which is used to obtain the biomolecule mass surface concentration variation brought by biomolecule interaction. With an optimal azimuth setting of polarization elements $\mathrm{P}, \mathrm{C}$ and $\mathrm{A}$ for a high contrast of imaging, the detected intensity is approximately linearly proportional to the thickness corresponding to the surface concentration [27]. As for the same protein and the same ellipsometric conditions, the absolute value of the thickness can be determined by the protein layer with known intensity in grayscale [28]. The label-free sampling method for the detection of ligand and receptor interaction may effectively avoid several problems in proteins labelling mentioned by Thomas Kodadek [21], such as quantitative difficulty, protein denaturation, laborintensive label processing, etc.

2.6 Calibration for quantitative detection Imaging ellipsometry may visualize protein layer with image in grayscale and the value of grayscale is proportional to biomolecule mass surface concentration, so it may qualitatively explain the state of protein layer. If one wants to analysis protein interactions and their results quantitatively, some auxiliary experiments should be performed for calibration. Usually the refractive index of saturated protein layers in visible light region is in the range of 1.4-1.5 [29], and the related variation of layer thickness is interested, but not the absolute value of the thickness, so it's simplified that the refractive indices of protein layers are supposed same. In this case, a series of the interested protein solutions with different concentration is used to get a series of protein detection results within a certain interaction time, which results in a calibration curve between the ellipsometric signal and the protein concentration in the solution, so that the unknown concentration can be calibrated with the curve.

The absolute thickness of the protein layer is calibrated by conventional ellipsometry. The relationship between the biomolecule mass surface concentration and protein layer thickness $(d)$ is the surface concentration $\Gamma\left(\mu \mathrm{g} / \mathrm{cm}^{2}\right) \approx K d$ (nm), where $K \approx 0.12 \mu \mathrm{g} / \mathrm{cm}^{2} \mathrm{~nm}$ [30].

2.7 Control system and database Biosensor based on imaging ellipsometry consists a powerful software available for image acquisition, image processing, and system control. It combines automatic control algorithms with the requirement of experiment, including:

- Microfluidic control: solution delivery order, fluidic velocity, duration of flow, etc.,

- Imaging acquisition including snapshot image grab, sequence image grab and programmable image grab, etc.,

- Image analysis: microarray localization, dynamic range definition, calibration in grayscale,

- Automatic focusing,

- Self-adjustment of imaging contrast,

- Automatic enactment of ellipsometric state,

- Automatic calculation of grayscale in sample area,

- Automatic computation of dynamic scale of grayscale,

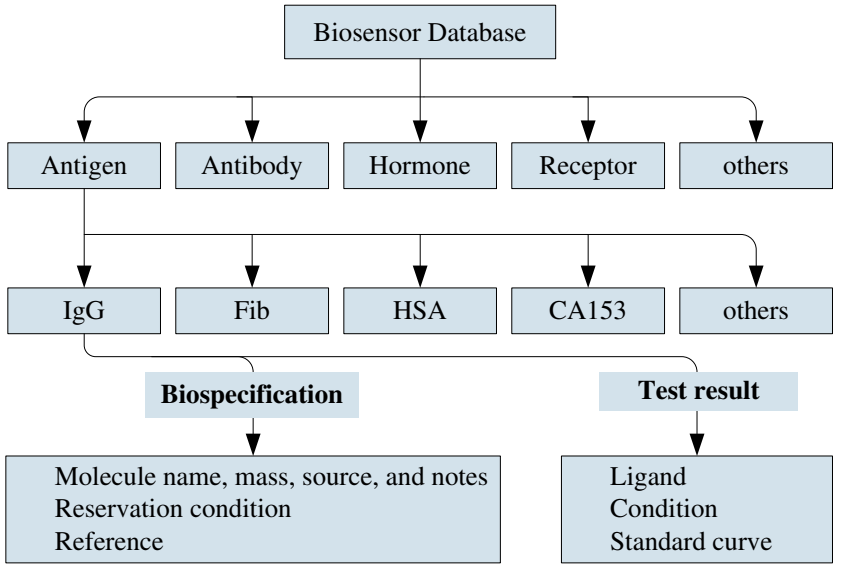

Figure 4 (online colour at: www.pss-a.com) Schematic of biosensor database.

- Automatic reducing system noise with sequence images average, background removing, etc.

Biosensor database which schematic is shown in Fig. 4, hosts some of the most important collections of the experiment data on the biosensor based on imaging ellipsometry, including antigen-antibody, incretion, ligandreceptor, even virus, etc. The database is composed of the data from experiments and samples, which was available and helpful for users, and the users would be further contributors to add their results into the database. The database hosts several research groups and some scientists continually develop new way for the biosensor community.

2.8 Biosensor with total internal reflection imaging ellipsometry A recent biosensing development is a microfluidic reactor array combined with total internal reflection imaging ellipsometry [31] as shown in Fig. 5. It is realized as an automatic analysis for protein interaction processes with real-time label-free method. The total internal reflection imaging ellipsometry system is performed in the internal reflection mode which the refractive index of the incident medium is larger than that of the reflecting medium and the incident angle is larger than the critical angle of total reflection. An evanescent field appeared in the reflecting medium which is used to measure biomolecule interaction. The prism contacted with a glass slide is used to realize the internal reflection. The other side of the slide is coated with a thin gold film as a substrate for ligand immobilization and contacted tested solutions. The probe beam passes through a polarizer, compensator, perpendicularly into the window of glass prism and finally onto the gold film. Under the total internal reflection, the evanescent field appeared on the substrate surface, which is modified by depositions of biomolecule layers on the surface, so that the polarization state of reflection is modified.

With the analysis of the polarized state of reflection, the information of these biomolecule layers can be deduced to realize a biosensor function. The use of evanes- 


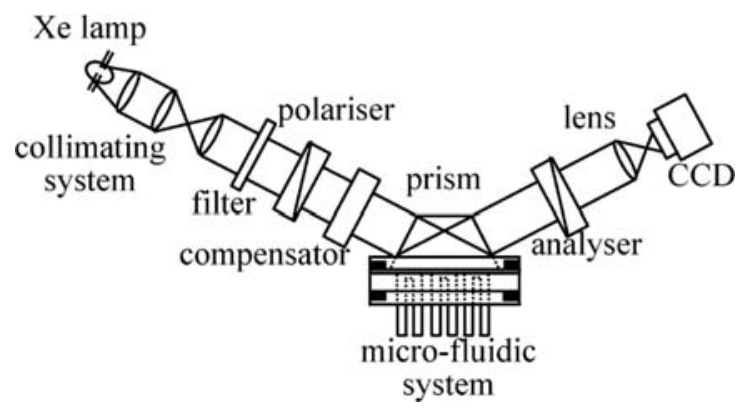

Figure 5 Schematic of biosensor with total internal reflection imaging ellipsometry, which was cited from [31].

cent field makes measurements not be disturbed by refractive index non-uniformity and flow of solution. With a micro-fluidic system including an $8 \times 6$ cell array with $100 \mathrm{nl}$ volume each cell, the function of microarray biosensor is realized, by which multiple biomolecule interaction process can be measured in a real time experiment model.

3 Results and discussion So far the applications of this technique mainly focused on biomedical fields. The technique have been used successfully for the biomolecule interaction [5], the hormone detection [32], the cell factor and its receptor interaction [33], the cancer marker test [34], the mono-clone medicine evaluation $[35,36]$, the clinic diagnosis for hepatitis B [6], the quantitative protein competitive adsorption $[25,37,38]$, the kinetic detection for multi-protein interaction process $[5,39]$, and the virus detection [40, 41], etc.

With the biosensor based on imaging ellipsometry, a 48 channel parallel analysis is realized for protein detection or identification. Figure 6 shows a result of a protein microarray with 48 bioactivity units for a parallel test at the same time. The silicon surface is modified with 3-aminopropyl-triethoxysilane (APTES) and glutaraldehyde [11] forming aldehyde groups for ligand immobilization.

For each unit in the microarray, it is prepared with one kind of ligand immobilization, and then blocked. It is used to test its corresponding receptor or used as a control within $40 \mathrm{~min}$. From the top left corner to the bottom right corner of the microarray, lines are coded in number and rows coded alphabetically.

The $1 \times(\mathrm{A}, \mathrm{B}, \mathrm{C})$ and $1 \times(\mathrm{D}, \mathrm{E}, \mathrm{F})$ units with Hepatitis B surface antibody (HBsAb) and Hepatitis B surface antigen $(\mathrm{HBsAg})$ as ligands are used to test $\mathrm{HBsAg}(1 \mathrm{ng} / \mathrm{ml})$ positive standard serum in $1 \mathrm{~A}$ and $\mathrm{HBsAb}(1 \mathrm{IU} / \mathrm{ml})$ positive standard serum in $1 \mathrm{D} ; 1 \mathrm{~B}, 1 \mathrm{E}$ and $1 \mathrm{C}, 1 \mathrm{~F}$ as negative references and controls. These results show that the sensitivity for Hepatitis B surface antibody and Hepatitis B surface antigen reached to the clinical standard.

As a demonstration model, human fibrinogen (h-Fib) and human immunoglobulin $\mathrm{G}(\mathrm{h}-\mathrm{IgG})$ are chosen as
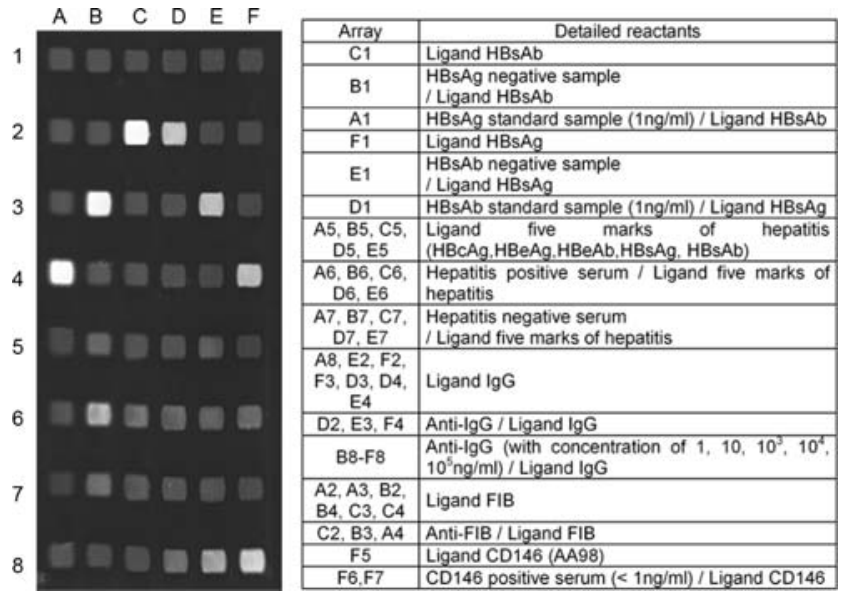

Figure 648 protein arrays in matrix. Left: The visual result of a protein micro-array. Right: The detailed reactants relative to the left graph.

ligand to test their antibodies. The 9 units in $(2,3,4) \times$ $(\mathrm{A}, \mathrm{B}, \mathrm{C})$ with $\mathrm{h}$-Fib as ligand are to test goat antibody $(0.1 \mathrm{mg} / \mathrm{ml})$ against $\mathrm{h}$-Fib in $2 \mathrm{C}, 3 \mathrm{~B}, 4 \mathrm{~A}$, and the rest as controls. The 9 units in $(2,3,4) \times(\mathrm{D}, \mathrm{E}, \mathrm{F})$ with $\mathrm{h}$-IgG as ligand are to test its antibody $(0.1 \mathrm{mg} / \mathrm{ml})$ in $2 \mathrm{D}, 3 \mathrm{E}, 4 \mathrm{~F}$, and the rest as controls. These experiments are normal check for the clinical situation.

The each row in $(5,6,7) \times(\mathrm{A}, \mathrm{B}, \mathrm{C}, \mathrm{D}, \mathrm{E})$ with Hepatitis $B$ core antigen ( $\mathrm{HBcAg}$ ), Hepatitis $B$ e antigen (HBeAg), Hepatitis B e antibody (HBeAb), HBsAg, and $\mathrm{HBsAb}$ as ligands, respectively, are to test Hepatitis B positive serum in the line $6 \times(\mathrm{A}, \mathrm{B}, \mathrm{C}, \mathrm{D}, \mathrm{E})$, and Hepatitis $\mathrm{B}$ negative serum in the $7 \times(\mathrm{A}, \mathrm{B}, \mathrm{C}, \mathrm{D}, \mathrm{E})$ as well as the $5 \times(\mathrm{A}, \mathrm{B}, \mathrm{C}, \mathrm{D}, \mathrm{E})$ as a control. This test is significant for a clinic purpose.

The $(5,6,7) \times \mathrm{F}$ with antibody AA98 against human CD146 as ligand are used to test human CD146 positive serum $(<1 \mathrm{ng} / \mathrm{ml})$ in $5 \mathrm{~F}$ and $6 \mathrm{~F}$, respectively; $7 \mathrm{~F}$ as a control.

In order to show the dynamic range of protein detection, the $8 \times(\mathrm{A}, \mathrm{B}, \mathrm{C}, \mathrm{D}, \mathrm{E}, \mathrm{F})$ with $\mathrm{H}-\mathrm{IgG}$ as ligand to test anti-H-IgG produced in goat with several concentration of $0.001,0.01,1,10,100 \mu \mathrm{g} / \mathrm{ml}$ in $8 \times(\mathrm{B}, \mathrm{C}, \mathrm{D}, \mathrm{E}, \mathrm{F})$, respectively, and $8 \mathrm{~A}$ as a reference. The relationship between the concentration of detected the anti-H-IgG and the biosensor output value in grayscale with five concentrations of the anti-H-IgG was shown in Fig. 7, which could be used as a calibration. It was a standard experiment for a concentration gradient normally used for the quantification.

4 Conclusion Within last ten years, the biosensor based on imaging ellipsometry has been developed as an automatic analysis technique for protein detection, with properties of label-free, multi-protein parallel analysis, and real-time analysis for protein interaction process, etc. Although it had shown a potential in application fields, it could be foreseen some further development in its simpli- 


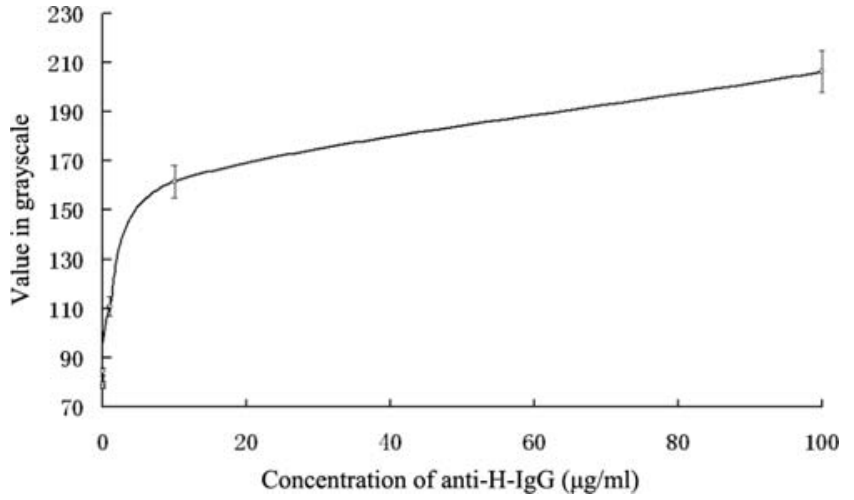

Figure 7 Biosensor output value in grayscale with the concentration of anti-H-IgG.

fied application system and function improvement, such as an integrated system, the sensitivity and throughput increase as well as a friendly operation system.

Acknowledgements The author gratefully acknowledges the support of National Natural Science Foundation of China, Chinese Academy of Sciences and K. C. Wong Education Foundation, Hong Kong.

\section{References}

[1] G. Jin, P. Tengvall, I. Lundstrom, and H. Arwin, Anal. Biochem. 232, 69 (1995).

[2] G. Jin, R. Jansson, and H. Arwin, Rev. Sci. Instrum. 67, 2930 (1996).

[3] G. Jin and Z. H. Wang, Int. J. Nonlinear Sci. Numer. Simul. 3, 191 (2002).

[4] G. Jin, Z. H. Wang, Y. H. Meng, P. Q. Ying, and L. H. Xia, in: Proceedings 23rd Annual International Conference of the IEEE Engineering in Medicine and Biology Society, Istanbul, Turkey, 2001, p. 158.

[5] Z. H. Wang and G. Jin, Anal. Biochem. 75, 6119 (2003).

[6] Z. H. Wang, Y. H. Meng, P. Q. Ying, C. Qi, and G. Jin, Electrophoresis 27, 4078 (2006).

[7] S. K. Bhatia, L. C. Shriver-Lake, K. J. Prior, J. H. Georger, J. M. Calvert, R. Bredehorst, and F. S. Ligler, Anal. Biochem. 178, 408 (1989).

[8] L. C. Shriver-Lake, B. Donner, R. Edelstein, K. Breslin, S. K. Bhatia and F. S. Ligler, Biosens. Bioelectron. 12, 1101 (1997).

[9] L. Vroman, A. L. Adams, G. C. Fischer, and P. C. Munoz, Blood 55, 156 (1980).

[10] L. Vroman and A. L. Adams, Surf. Sci. 16, 438 (1969).

[11] Z. H. Wang and G. Jin, J. Immunol. Meth. 285, 237 (2004).

[12] H. Yuan, W. M. Mullett, and J. Pawliszyn, Analyst 126, 1456 (2001).

[13] J. Lin, J. Herron, J. D. Andrade, and M. Brizgys, IEEE Trans. Biomed. Eng. 35, 466 (1988).

[14] M. Yoshioka and Y. Mukai, J. Chromatogr. B 566, 361 (1991).

[15] C. M. Halliwell and A. E. G. Cass, Anal. Chem. 73, 2476 (2001).
[16] Z. H. Wang and G. Jin, J. Biochem. Biophys. Methods 57, $203(2003)$

[17] Z. H. Wang and G. Jin, Colloid Surf. B, Biointerfaces 34, 173 (2004).

[18] C. Qi, X. S. Tian, J. H. Yan, F. Gao, and G. Jin, in: 4th International Conference on Spectroscopic Ellipsometry, Stockholm, Sweden, 2007, p. 349.

[19] H. W. Ma, D. J. Li, X. Sheng, and B. Zhao, Langmuir 22, 3751 (2006)

[20] J. He, Y. Wu, J. Wu, C. Xiong, Y. Meng, G. Jin, and H. Ma, in: Program and Abstracts of 4th International Conference on Spectroscopic Ellipsometry, Stockholm, Sweden, 2007, p. 169.

[21] T. Kodadek, Chem. Biol. 8, 105 (2001).

[22] A. Talapatra, R. Rouse, and G. Hardiman, Pharmacogenomics 3, 527 (2002).

[23] G. MacBeath and S. L. Schreiber, Science 289, 1760 (2000).

[24] M. F. Templin, D. Stoll, M. Schrenk, P. C. Traub, C. F. Vohringer, and T. O. Joos, Drug Discov. Today 7, 815 (2002).

[25] O. Hofmann, G. Voirin, P. Niedermann, and A. Manz, Anal. Chem. 74, 5243 (2002).

[26] Y. H. Meng and G. Jin, J. Test Meas. Technol. NCIT 14, $220(2000)$

[27] Y. Y. Chen, Y. H. Meng, and G. Jin, Appl. Opt. 46, 8475 (2007).

[28] P. Q. Ying, Y. Yu, G. Jin and Z. L. Tao, Colloid Surf. B, Biointerfaces 32, 1 (2003).

[29] H. Arwin, Appl. Spectrosc. 40, 313 (1986).

[30] M. Stenberg and H. Nygren, J. Phys. (France) 44, 83 (1983).

[31] Y. Y. Chen, Z. H. Wang, Y. H. Meng, and G. Jin, Int. J. Nanotechnol. 4, 171 (2006).

[32] Z. Y. Zhao, G. Jin, and Z. H. Wang, in: Proceedings 20th International Conference of the IEEE Engineering in Medicine and Biology Society, Hong Kong, China, 1998, pp. 269-272.

[33] Z. H. Wang and G. Jin, Chin. J. Biotechnol. 18, 99 (2002).

[34] H. G. Zhang, C. Qi, Z. H. Wang, G. Jin, and R. J. Xiu, Clin. Chem. 51, 1038 (2005)

[35] J. Z. Duan, X. Y. Yan, X. M. Guo, W.-C. Cao, W. Han, C. Qi, J. Feng, D. L. Yang, G. X. Gao, and G. Jin, Biochem. Biophys. Res. Commun. 333, 186 (2005).

[36] J. Z. Duan, X. Ji, J. Feng, W. Han, P. H. Zhang, W. C. Cao, X. M. Guo, C. Qi, D. L. Yang, G. Jin, G. X. Gao, and X. Y. Yan, Antivir. Ther. 11, 117 (2006).

[37] P. Q. Ying, G. Jin, and Z. L. Tao, in: Proceedings 2nd European Medical and Biological Engineering Conference, Vienna, Austria, 2002, pp. 190/191.

[38] P. Q. Ying, G. Jin, and Z. L. Tao, Colloid Surf. B, Biointerfaces 33, 259 (2004).

[39] G. Jin, Z. Y. Zhao, Z. H. Wang, Y. H. Meng, and L. H. Xia, in: Proceedings IEEE conference, ISIK2000 Workshop on Biomedical Information Engineering, Istanbul, Turkey, 2000, pp. 137-140.

[40] C. Qi, J. Feng, Z. H. Wang, Y. H. Meng, X. Y. Yan, and G. Jin, Chin. J. Biotech. 22, 856 (2006).

[41] C. Qi, J. Z. Duan, Z. H. Wang, Y. Y. Chen, P. H. Zhang, L. Zhan, X. Y. Yan, W. C. Cao, and G. Jin, Biomed. Microdevices 8, 247 (2006). 